\title{
Effects of Water Stress on Germination and Growth of Linseed Seedlings (Linum usitatissimum L), Photosynthetic Efficiency and Accumulation of Metabolites
}

\author{
Rui Guo ${ }^{1}$, WeiPing Hao ${ }^{1} \&$ DaoZhi Gong ${ }^{1}$ \\ ${ }^{1}$ Institute of Environment and Sustainable Development in Agriculture (IEDA), Chinese Academy of \\ Agricultural Sciences (CAAS) / Key Laboratory of Dryland Agriculture, Ministry of Agriculture, Beijing, China \\ Correspondence: Rui Guo, Institute of Environment and Sustainable Development in Agriculture (IEDA), \\ Chinese Academy of Agricultural Sciences (CAAS) / Key Laboratory of Dryland Agriculture, Ministry of \\ Agriculture, Beijing 100081, China. Tel: 86-10-8210-5981. E-mail: guor219@yahoo.com
}

Received: May 7, 2012 Accepted: May 24, 2012 Online Published: September 13, 2012

doi:10.5539/jas.v4n10p253 URL: http://dx.doi.org/10.5539/jas.v4n10p253

\begin{abstract}
Drought is a serious problem in many nations, adversely affecting both crop growth and yield. Here, we investigate the effects of water stress on growth, photosynthesis, physiology and germination in seedlings of linseed (Linum usitatissimum L). Water stress was imposed by exposing the sand-grown roots to irrigation with a range of concentrations of polyethylene glycol-6000 (PEG). Both relative growth rate (RGR) and water content (WC) decreased with increasing PEG concentration with the reductions being greatest for $20 \%$ PEG (water potential $-0.58 \mathrm{MPa}$ ). The results show that as PEG concentration increased, the fluorescent chlorophyll and chloroplast pigments decreased but the ratio of $C h l \mathrm{a} / C h l \mathrm{~b}$ gradually increased. Meanwhile, shoot carbohydrate content increased slightly with increasing PEG concentration while that in the roots peaked at 5\% PEG $(-0.09$ MPa) before decreasing at higher PEG concentrations. The content of proline in shoots and roots increased with increasing PEG concentration. With increasing PEG concentration, betaine showed a slight tendency to rise in the root, but to rise and then fall in the shoot. The results indicate that PEG-induced water stress increased the accumulations of carbohydrate, proline and betaine. These may help the linseed seedlings to survive periods of osmotic stress induced by drought and may be involved in the perception and transmission a drought signal, also playing a role in osmotic adjustment. Under water stress, the main inorganic ions involved in osmotic adjustment were $\mathrm{K}^{+}, \mathrm{Na}^{+}, \mathrm{Ca}^{2+}$ and $\mathrm{Cl}^{-}$likely thereby increasing drought resistance. The germination percentage of the seeds was severely reduced by increasing PEG concentrations, ceasing altogether at $15 \%$ PEG. Many of the seeds that remained dormant in the higher PEG concentrations germinated satisfactorily when afterwards placed in pure water. The research provides useful leads in the planned development of linseed cultivars having increased drought tolerance.
\end{abstract}

Keywords: water stress, PEG-6000, wheat, growth, chlorophyll fluorescence, metabolites

\section{Introduction}

Especially over the last 100 years, our unbridled exploitation of the world's natural resources has severely damaged its vegetation and has also resulted in worrying accumulations of industrial wastes and greenhouse gases. Together, these have upset natural ecosystem balances and have created many environment and climatic problems, including rising temperatures, increasing desertification, serious soil loss, soil salinization and damaging accumulations of soil nitrogen (Abrol et al., 1988; Richards, 1990; Pawl, 1998; Rengasamy, 2002). In many nations, the recent increased incidences of severe drought and associated desertification are coming into especially sharp focus because of their sudden, long term and devastating consequences for the local human population.

Drought imposes one of the commonest and most significant constraints to agricultural production, seriously affecting crop growth, gene expression, distribution, yield and quality (Steudle \& Peterson, 1998; Zhao et al., 2009). In China in the 1970s, the area of agricultural land affected by drought was $1.13 \times 10^{7} \mathrm{hm}^{2}$ but by the 1990s (a 20-year period) the affected area had increased more than twofold to $2.667 \times 10^{7} \mathrm{hm}^{2}$. In recent years, conflicts between population growth, increasing urbanisation, agricultural development and environmental degradation have come to prominence. These suggest that much greater attention should be paid to research on 
crop biology under adverse conditions (Shi et al., 2008).

Plants have evolved a number of mechanisms to adapt to and survive all kinds of biotic and abiotic stresses. These include photosynthetic mechanisms, osmoregulation and antioxidant enzymes. Photosynthesis is probably the most fundamental of the metabolic process in plants and this has become a major research focus in physiological-ecology being recognised as being particularly critical to plant success and survival (Liu et al., 2007).

Linseed (Linum usitatissimum L) is a diploid, self-pollinated, annual crop, with modern cultivars being typically short, many branched and producing large amounts of seed (Deyholos, 2006). It is one of the earliest cultivated plants known and, since ancient times, it has been grown widely for its high-quality, cellulose-rich, bast fibers and also for its oil (Zohary \& Hopf, 2004; Huis et al., 2010). The oil of linseed is an excellent nutritional supplement being rich in $\alpha$-linolenic acid and omega-3 fatty acid. The oil is also used in the production of industrial raw materials (Vaisey-Genser \& Morris, 2003; Foster et al., 2009; McKenzie \& Deyholos, 2011). In the textile industry, the fibers of linseed have been largely replaced by cotton or by synthetic fibers but they are still used in the high-quality linen materials and are also now being incorporated in the polymeric matrix of biocomposites to improve their mechanical properties (Chemikosova et al., 2006; Bodros et al., 2007; Huis et al., 2010). In 2009, the top producers of linseed were Canada, India and China, with $45 \%$ of world production being in Canada (FAO, 2009).

The purpose of this study was to investigate the effects of water stress on the germination and growth of linseed seedlings, including effects on chlorophyll fluorescence and on accumulations of proline, betaine and carbohydrates. It was also desired to elucidate mechanisms of water stress damage and to identify possible adaptive mechanisms to water stress. Understanding how linseed manages water stress is important for the reclamation of drought-prone soils and crop production, and possibly also to discover water-stress resistance genes and hence to develop drought-resistance biotechnology in this crop.

\section{Materials and Methods}

\subsection{Design of Simulated Water Stress Conditions}

Water stress conditions were simulated by exposing germinating linseed plants to polyethylene glycol-6000 (PEG) at one of five concentrations: $0,5,10,15$ and $20 \%(\mathrm{w}: \mathrm{w})$. The osmotic potentials of the solutions was measured using a water potential meter (Psypro Wescor Corporation, US). Table 1 results shows how osmotic potential decreases with increasing PEG-6000 concentration.

Table 1. The osmotic potential (OP) of solutions of polyethylene glycol (PEG)

\begin{tabular}{cccccc}
\hline $\begin{array}{c}\text { Water stress } \\
\text { (PEG-6000 concentration) }\end{array}$ & $0 \%$ & $5 \%$ & $10 \%$ & $15 \%$ & $20 \%$ \\
\hline OP $(\mathrm{MPa})$ & -0.05 & -0.09 & -0.19 & -0.36 & -0.58 \\
\hline
\end{tabular}

\subsection{Plant Materials and Growing Conditions}

Seeds of linseed (Linum usitatissimum L) NingYa-15 were sown 20 seeds per pot in 17-cm diameter plastic pots each containing $2.5 \mathrm{~kg}$ of washed sand. Seedlings were watered daily with 0.5 Hoagland's nutrient solution $\left(\mathrm{KH}_{2} \mathrm{PO}_{4}, \mathrm{KNO}_{3}, \mathrm{Ca}\left(\mathrm{NO}_{3}\right)_{2}, \mathrm{MgSO}_{4}, \mathrm{H}_{3} \mathrm{BO}_{3}, \mathrm{MnCl}_{2} \cdot 4 \mathrm{H}_{2} \mathrm{O}, \quad \mathrm{ZnSO}_{4} \cdot 7 \mathrm{H}_{2} \mathrm{O}, \mathrm{CuSO}_{4} \cdot 5 \mathrm{H}_{2} \mathrm{O}, \mathrm{H}_{2} \mathrm{MoO}_{4} \cdot \mathrm{H}_{2} \mathrm{O}\right.$, FeEDTA). All pots were placed outdoors but were sheltered from the rain. The day/night temperature range experienced during the experiment was $21.0-25.5^{\circ} \mathrm{C} / 18.5-21.0^{\circ} \mathrm{C}$. After four weeks, 30 pots containing uniform seedlings were selected and randomly divided into six sets of five replicates. One set was used to determine the seedling growth parameters just prior to treatment, a second set was used as the untreated control ( $0 \%$ PEG- 6000 , watered with Hoagland's nutrient solution), and the four remaining sets were stressed with one or other of the PEG-6000 solutions. Each PEG subtreatment was applied to a set of five pots, daily for 7 days.

\subsection{Measurement of Growth}

After the seventh day of treatment, all seedlings in a pot were separated from the sand, washed with ultra-pure water and the shoot divided from the root. The fresh weights (FW) were recorded after removing surface water by blotting and the dry weights (DW) determined after drying for $15 \mathrm{~min}$ in an oven at $80^{\circ} \mathrm{C}$ and then in a vacuum dryer at $40^{\circ} \mathrm{C}$ to constant weight. The relative growth rate (RGR) was defined as (ln DW after treatment - ln DW before treatment) / treatment duration (Kingsbury et al., 1984). The water content (WC) percentage was calculated as: $100 \times(\mathrm{FW}-\mathrm{DW}) / \mathrm{FW}$ (Yang et al., 2008). 


\subsection{Measurement of Chlorophyll Fluorescence, Pigments and Light Response Curve}

The maximal photochemical efficiency of PSII (PSII=Fv/Fm), the photosynthetic efficiency of PSII $\left(\mathrm{Y}_{(\mathrm{II})}=\mathrm{Fm}\right.$ '-F/Fm'), non-photochemical quenching (NPQ=Fm-Fm'/Fm'), non-photochemical quenching coefficient (qN=Fm-Fm'/Fm-Fo'), photochemical quenching ( $\mathrm{qP}=\mathrm{Fm}$ '-F/Fm'-Fo'), the efficiency of excitation energy capture by open PSII reaction centers ( $\left.\mathrm{Fv}^{\prime} / \mathrm{Fm}^{\prime}\right)$ and apparent photosynthetic electron transport rate (ETR) were determined between 09:00 and 11:00 h from fully-expanded leaves using an Imaging-PAM (Walz, Effeltrich, Germany) (Genty et al., 1989; Van \& Snel, 1990). The leaves were held in the dark for about 20 min before measurement. The intensities of the actinic and saturating light settings were $185 \mu \mathrm{mol} / \mathrm{m}^{2} \mathrm{~s}$ and $2500 \mu \mathrm{mol} / \mathrm{m}^{2} \mathrm{~s}$ PAR, respectively. The contents of carotenoids (Car) and chlorophyll (Chl) $a$ and $b$ were extracted using acetone, and spectrophotometeric determination at 440, 645 and $663 \mathrm{~nm}$ of each sample was done three times. The calculations used the Equations of Arnon (1949). The light response curves of the leaves were determined by the White and Critchley method (1999).

\subsection{Measurement of Cations and Anions}

The quantities of cations $\left(\mathrm{Na}^{+}, \mathrm{K}^{+}, \mathrm{Ca}^{2+}\right.$ and $\left.\mathrm{Mg}^{2+}\right)$ were determined using an atomic absorption spectrophotometer (TAS-990, Purkinje General, Beijing). The quantities of anions $\left(\mathrm{NO}_{3}{ }^{-}, \mathrm{Cl}^{-}, \mathrm{SO}_{4}{ }^{2-}\right.$ and $\mathrm{H}_{2} \mathrm{PO}_{4}{ }^{-}$) were determined by ion exchange chromatography (DX-300 ion chromatographic system; AS4A-SC ion-exchange column, CD M-II electrical conductivity detector; DIONEX, Sunnyvale, USA) with a mobile phase comprising 1.7/1.8 $\mathrm{mM} \mathrm{Na}_{2} \mathrm{CO}_{3} / \mathrm{NaHCO}_{3}$ (Yang et al., 2007).

\subsection{Measurement of Proline, Betaine and Carbohydrates}

Proline was extracted with $3 \%$ sulfosalicylic acid for $30 \mathrm{~min}$ at $70^{\circ} \mathrm{C}$ and measured with ninhydrin (Zhu et al., 1983). Betaine was extracted with $80 \%$ methanol for $20 \mathrm{~min}$ at $70^{\circ} \mathrm{C}$ and measured as described by Grieve and Grattan (1983). Samplings were dried and cut into many small pieces before being analysed by the anthracene ketone method: a $50 \mathrm{~g}$ sample from each treatment was dipped in $3 \mathrm{~cm}^{3}$ of $80 \%$ ethanol:water at $80^{\circ} \mathrm{C}$ for about $40 \mathrm{~min}$; centrifuged at $3000 \times \mathrm{g}$ for $15 \mathrm{~min}$ and the supernatant collected. The polycondensation with anthrone resulted in a blue compound (Zhou et al., 2002). The leaf carbohydrate content was measured with a UV-754 spectrophotometer at $620 \mathrm{~nm}$. Each measurement was repeated three times (Shi \& Guo, 2006).

\subsection{Measurement of Germination}

One hundred linseed seeds were germinated on filter paper in germination boxes. The dry seeds were submerged in $100 \mathrm{~mL}$ of each of the PEG-6000 solutions described above (with distilled water as the control). The boxes were maintained at $20^{\circ} \mathrm{C}$ in the dark for $10 \mathrm{~d}$, five replicates of each PEG treatment were prepared. Percentages of germinated seeds were scored daily, based on the emergence of the radicles. Afterwards, ungerminated seeds were transferred to distilled water to determine whether they would germinate during a $7 \mathrm{~d}$ recovery period.

\section{Statistical Analysis}

Statistical analyses of variance and correlations were done with the statistical application SPSS 13.0. All treatments were replicated five times, and means and calculated standard errors (S.E.) are reported.

\section{Results}

\subsection{Growth}

The RGRs and WCs of shoots and roots all decreased with increasing PEG concentration, with the greatest reductions occurring under the highest water stresses (Figure $1 \mathrm{~A}, P \leq 0.05$ ). From the slopes of Equations (1) and (2) (Table 2), it was calculated that the RGR for shoot and root increased by 0.88 and 1.17, respectively, per 100 $\mathrm{mM}$ increase in PEG-6000 concentration. Meanwhile, the WC of shoot and root decreased by 165.17 and 140.84, respectively, for each $100 \mathrm{mM}$ increase in PEG concentration (see Equations (3) and (4) in Table 2).

Table 2. A regression analysis between RGR, WC and PEG concentration was performed, where $Y_{\mathrm{S}}$ represented the shoot RGR and WC, $Y_{\mathrm{R}}$ the root, and $x$ was PEG concentration (Table 2)

\begin{tabular}{ccccc}
\hline & \multicolumn{2}{c}{ Regression equation } & $R^{2}$ & $\begin{array}{c}\text { Decrease in RGR and WC per 10 } \\
\text { PEG concentration increased }\end{array}$ \\
\hline \multirow{2}{*}{ RGR } & $Y_{\mathrm{S}}=-0.0088 \mathrm{x}+0.5655$ & $(1)$ & 0.3949 & 0.09 \\
& $Y_{\mathrm{R}}=-0.0117 \mathrm{x}+0.6207$ & $(2)$ & 0.8263 & 0.12 \\
\multirow{2}{*}{$\mathrm{WC}$} & $Y_{\mathrm{S}}=-1.6517 \mathrm{x}+90.405$ & $(3)$ & 0.7495 & 16.52 \\
& $Y_{\mathrm{R}}=-1.4084 \mathrm{x}+97.467$ & $(4)$ & 0.8509 & 14.08 \\
\hline
\end{tabular}



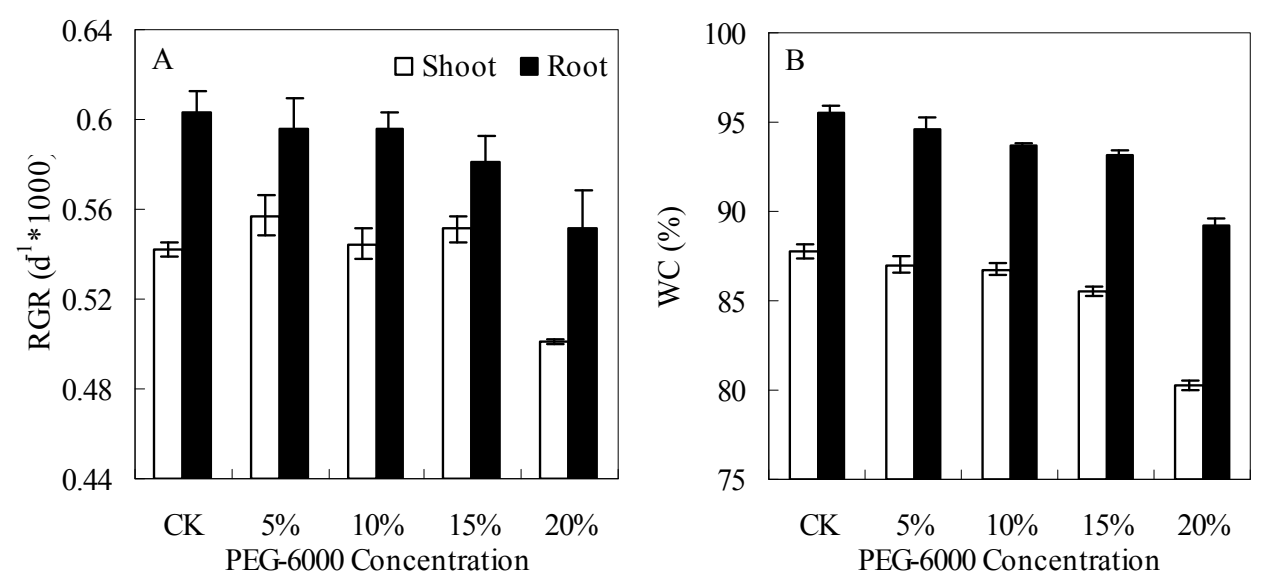

Figure 1. Effects of water stress on shoot (A) and root (B) relative growth rate (RGR) and water content (WC). The values are means of five replicates

\subsection{Chlorophyll Fluorescence, Pigments and Light-response Curve}

The PSII, Y(II), qP and ETR decreased with increasing PEG concentration, while NPQ and qN contents increased significantly, the effects were much more pronounced under high PEG concentration (Figure 2, A, B, $\mathrm{C}, \mathrm{D}, \mathrm{E}$ and $\mathrm{F} ; P \leq 0.05)$. The contents of $\mathrm{Chl} a$ and $\mathrm{Chl} b$ under PEG induced water stress were less than in the control, each parameter decreased gradually with increasing PEG concentration. The $\mathrm{Chl} a / b$ ratio was higher with PEG than in the control (Table 3, $P \leq 0.05$ ). The content of Car was scarcely changed by water stress (Table $3, P \leq 0.05)$. The trends of change in the light-response curves were similar, Figure 3 shows that increasing light intensity can promote photosynthesis at low light intensity, but that when light intensity reaches the saturation point, photosynthesis rate does not continue to increase but decreases with increasing PEG concentration $(P \leq 0.05)$.
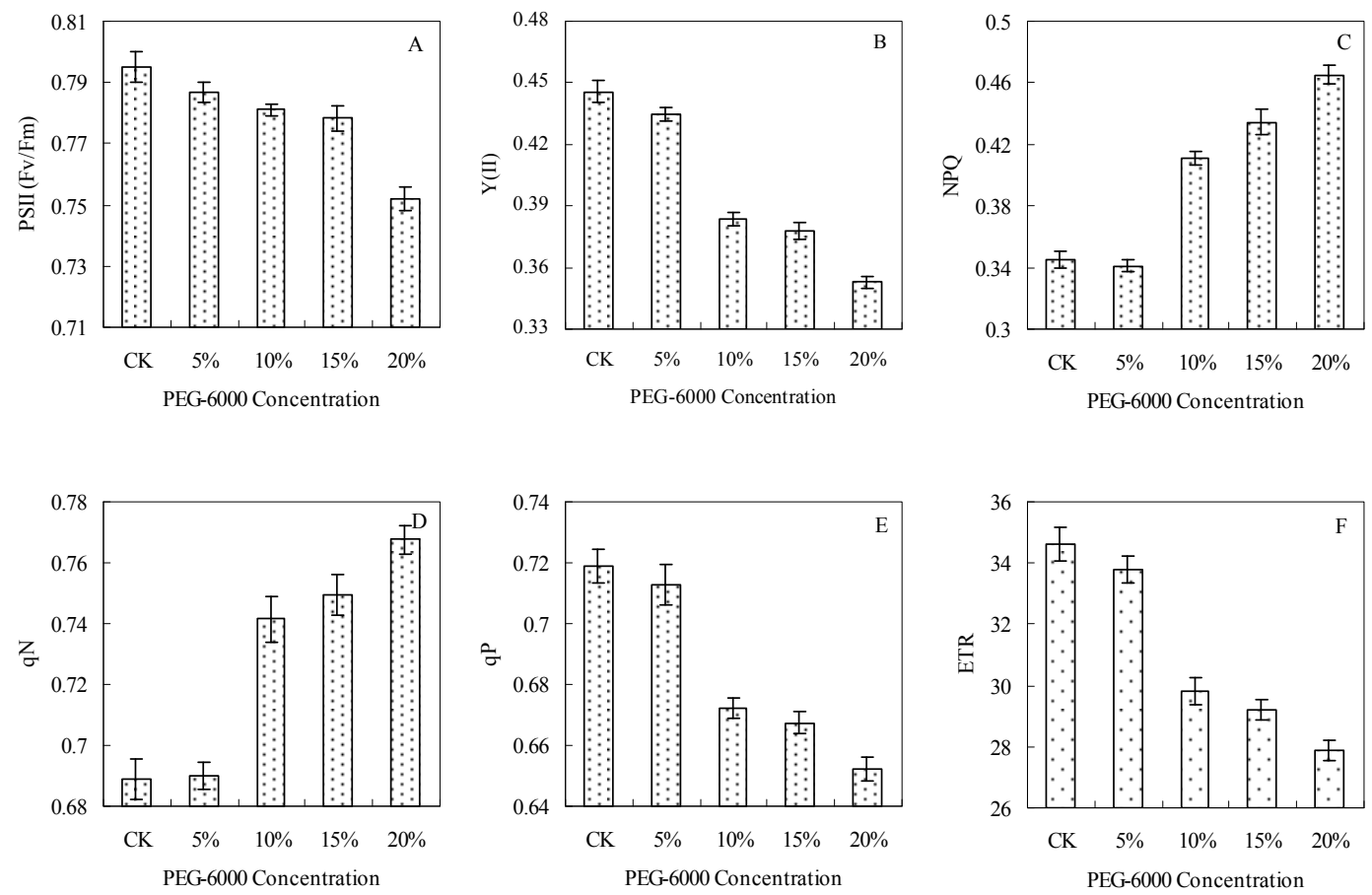

Figure 2. Effect of PEG induced water stress on six indices of photosynthesis in linseed determined through the measurement of chlorophyll $a$ fluorescence parameters. PSII (A), Y(II) (B), NPQ (C), qN (D), qP (E) and ETR

(F). The values are the means of five replicates 


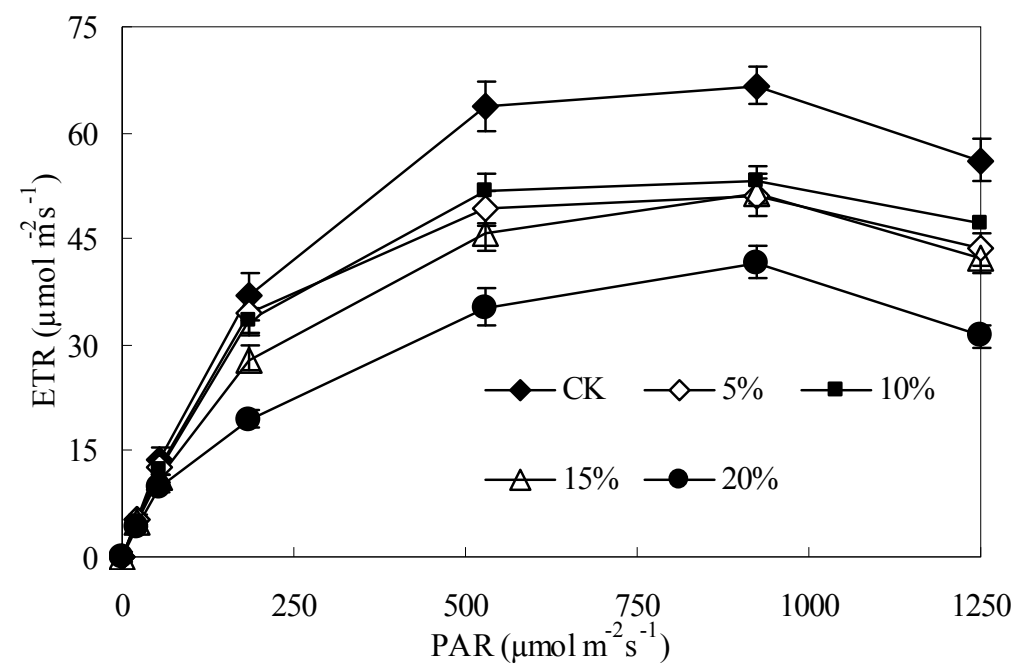

Figure 3. Representative light response curves for linseed leavers under water stress. The values are the means of five replicates

Table 3. Effects of water stress on contents of photosynthetic pigments (Chl - chlorophyll, Car - carotenoids) $(\mathrm{mg} / \mathrm{L})$ in seedlings of linseed. The values are the means of five replicates $\pm \mathrm{SD}$

\begin{tabular}{cccccc}
\hline PEG-6000 concentration & Chl $a$ & Chl $b$ & Chl $(a+b)$ & Chl $a / b$ & Car \\
\hline C & $6.55 \pm 0.13$ & $1.47 \pm 0.02$ & $8.02 \pm 0.16$ & $4.47 \pm 0.04$ & $2.67 \pm 0.05$ \\
$5 \%$ & $6.30 \pm 0.08$ & $1.30 \pm 0.02$ & $7.60 \pm 0.18$ & $4.85 \pm 0.08$ & $2.81 \pm 0.04$ \\
$10 \%$ & $6.63 \pm 0.11$ & $1.15 \pm 0.01$ & $7.77 \pm 0.12$ & $5.71 \pm 0.10$ & $2.72 \pm 0.08$ \\
$15 \%$ & $6.63 \pm 0.04$ & $1.09 \pm 0.03$ & $7.04 \pm 0.11$ & $5.52 \pm 0.09$ & $2.47 \pm 0.05$ \\
$20 \%$ & $5.86 \pm 0.08$ & $0.93 \pm 0.01$ & $6.79 \pm 0.15$ & $6.30 \pm 0.12$ & $2.38 \pm 0.07$ \\
\hline
\end{tabular}

\subsection{Carbohydrates}

Figure 4 A shows that total carbohydrates (TTC) and fructose in shoots increased slightly with rising PEG concentration, peaking with 5\% PEG, while sucrose contents decreased $(P \leq 0.05)$. In the roots, the highest TTC value was for $5 \%$ PEG (higher than for the control) (Figure 4, B; $P \leq 0.05$ ). The fructan and sucrose both decreased with increasing PEG concentration (Figure 4, B; $P \leq 0.05$ ).
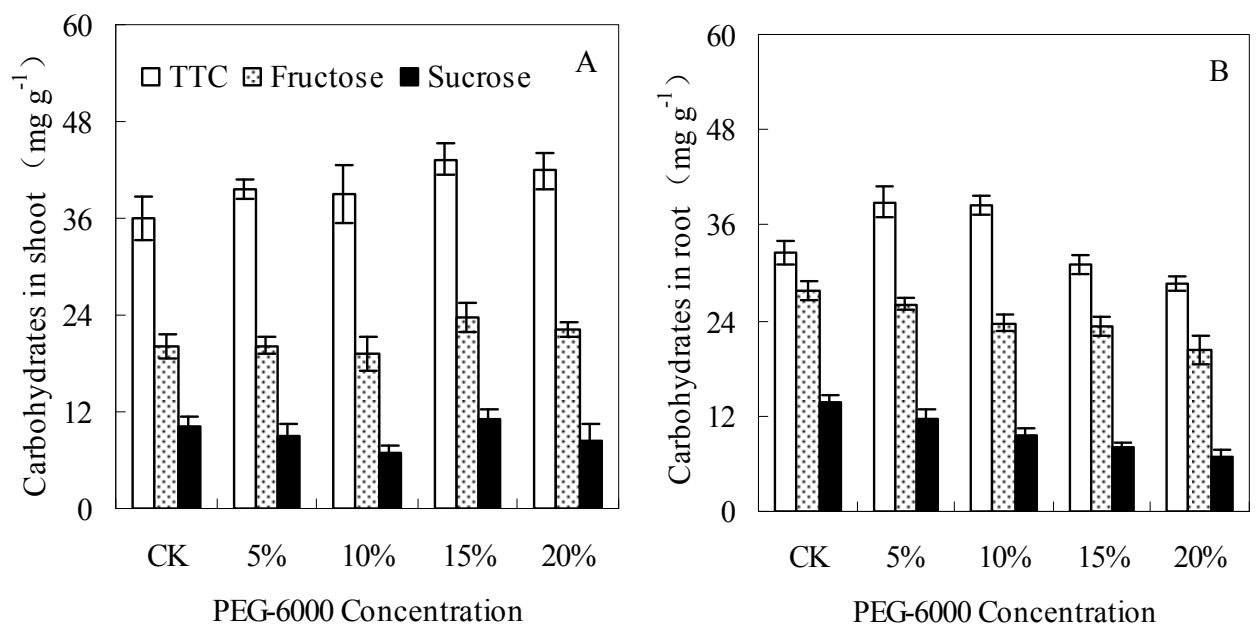

Figure 4. Effect of water stress on the contents of carbohydrates in shoot (A) and root (B). $\square$-The total carbohydrates (TTC); 7 -Fructose; $\mathbf{D}$-Sucrose. The values are the means of five replicates 


\subsection{Proline and Betaine}

The contents of proline increased with increasing PEG concentration, with that in the shoot being significantly higher than that in the root (Figure 5, A and B; $P \leq 0.05$ ). In the shoot, increasing water stress had a negative effect on betaine content (Figure 5, C; $P \leq 0.05$ ) but in the root a positive effect, causing a significant rise (Figure $5, \mathrm{D} ; P \leq 0.05)$.
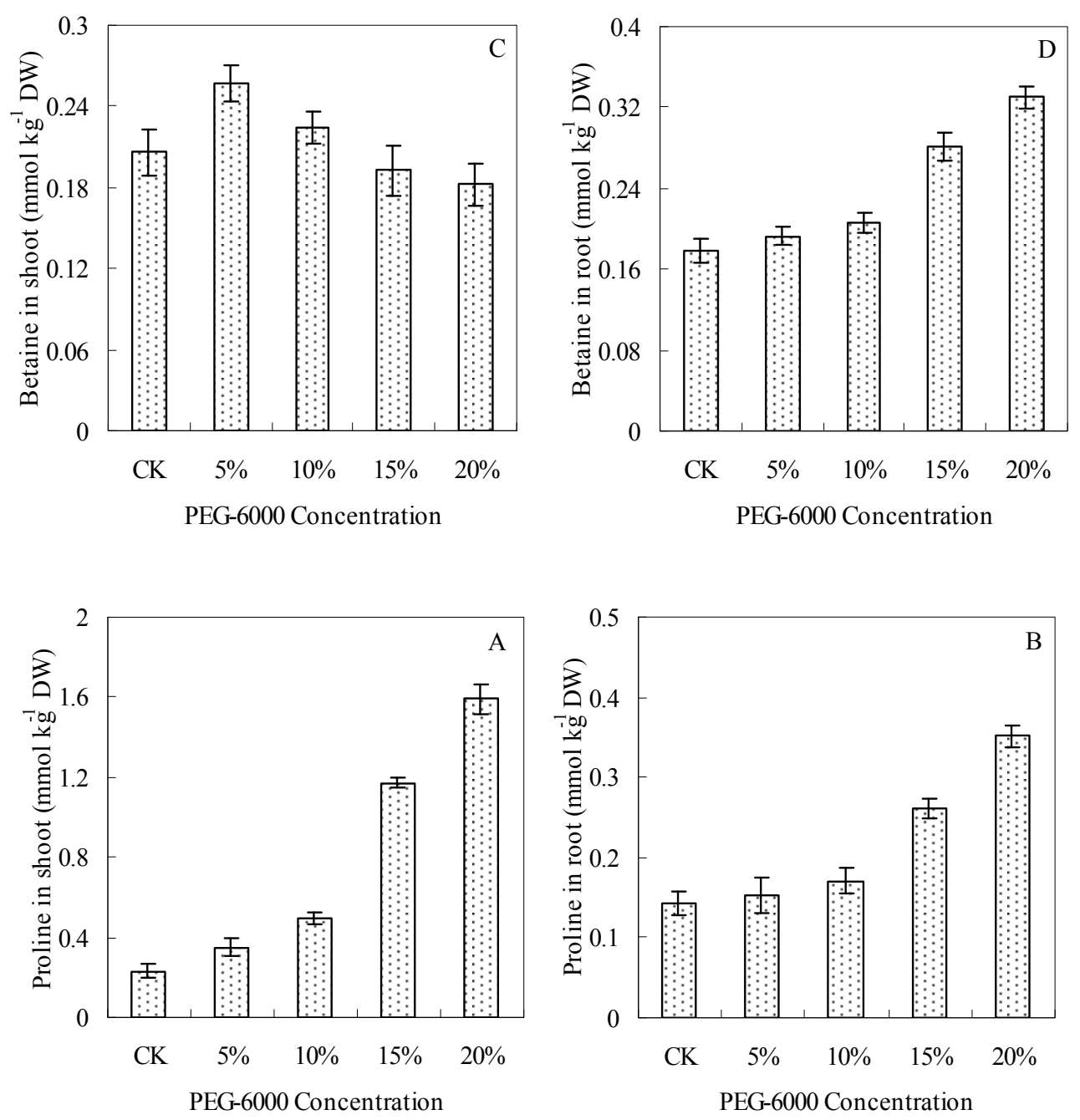

Figure 5. Effect of water stress on the contents of prolines in shoot (A) and root (B), the contents of betaines in shoot $(\mathrm{C})$ and root $(\mathrm{D})$. The values are the means of five replicates

\subsection{Ionic Balance}

With increasing PEG concentration, the $\mathrm{K}^{+}, \mathrm{Na}^{+}, \mathrm{Ca}^{2+}$ and $\mathrm{Mg}^{2+}$ contents decreased in both shoots and roots (Figure 6, A-D; $P \leq 0.05$ ) but the accumulation of $\mathrm{Na}^{+}$in roots was higher than in shoots, while that of $\mathrm{Ca}^{2+}$ in shoots was higher than in roots (Figure 6, B and C; $P \leq 0.05$ ). The content of $\mathrm{Fe}^{2+}$ increased significantly under low PEG concentrations but then declined dramatically with rising PEG concentration. Also, the extent of reduction in shoots was much greater than that in roots (Figure 6, E; $\mathrm{P} \leq 0.05$ ). There were little effects of water stress on $\mathrm{Cl}^{-}, \mathrm{H}_{2} \mathrm{PO}_{4}{ }^{-}$and $\mathrm{SO}_{4}{ }^{2-}$ contents, whereas $\mathrm{NO}_{3}{ }^{-}$decreased significantly. The contents of all were higher in the shoots than in the roots (Figure 6, F, G, H and I; $P \leq 0.05$ ). 

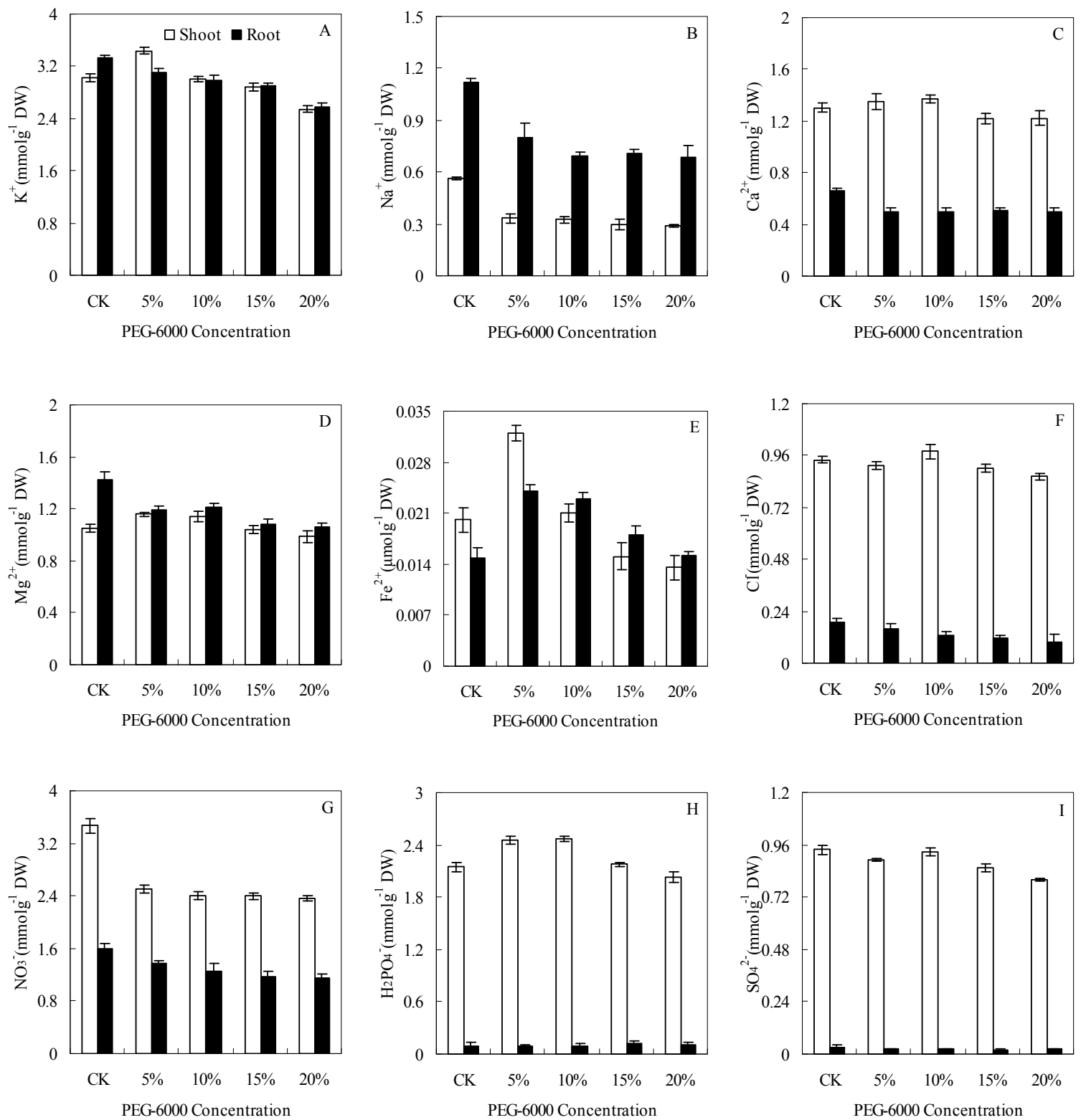

Figure 6. Effect of water stress on the concentrations of five inorganic cations: $\mathrm{K}^{+}(\mathrm{A}), \mathrm{Na}^{+}(\mathrm{B})$, free $\mathrm{Ca}^{2+}(\mathrm{C})$, $\mathrm{Mg}^{2+}(\mathrm{D})$ and $\mathrm{Fe}^{2+}(\mathrm{E})$; and four inorganic anions: $\mathrm{Cl}^{-}(\mathrm{F}), \mathrm{NO}_{3}^{-}(\mathrm{G}), \mathrm{H}_{2} \mathrm{PO}_{4}^{-}(\mathrm{H})$ and $\mathrm{SO}_{4}^{-}(\mathrm{I})$ in shoots and roots. The values are the means of five replicates

\subsection{Germination and Recovery Germination}

The germination percentage of linseed seeds decreased dramatically under PEG induced water stress with no germination occurring above 15\% PEG (Figure 7; $P \leq 0.05$ ). After the PEG treatments, when seeds were transferred to distilled water, some seeds germinated which had failed to in PEG. The recovery germination percentage increased strongly with increasing PEG concentration (Figure 7; $P \leq 0.05$ ). 


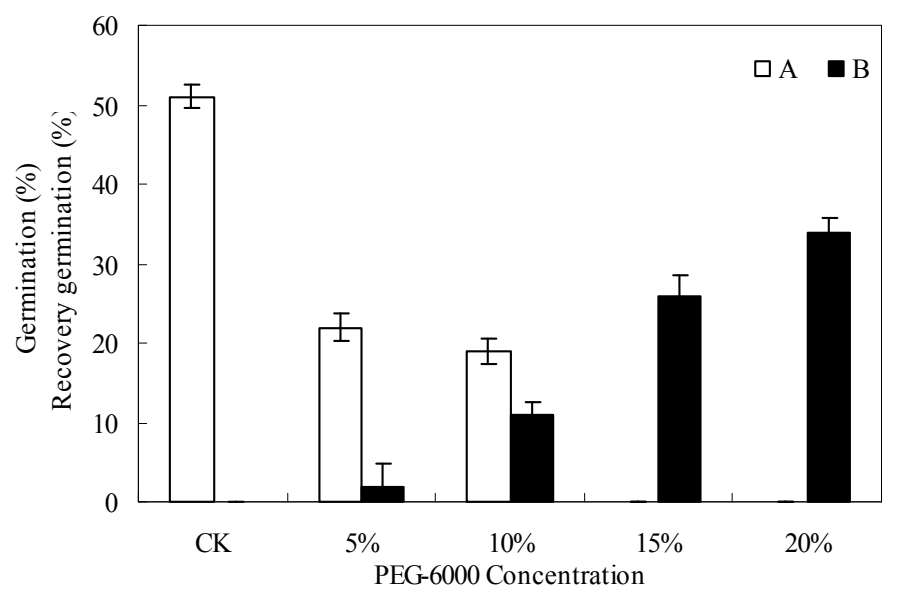

Figure 7. Effects of water stress on the rate of germination (A) in PEG and on subsequent recovery germination (B) in water. Values are the means of five replicates

\section{Discussion}

\subsection{Effect of Water Stress Treatments on Growth}

In plants in general, an appropriate growth strategy is key to fitness in a competitive situation, so too in linseed seedlings, their growth strategy is critical to survival (Ross \& Harper, 1972; Bush \& Van Auken, 1991; Paz \& Martinez-Ramos, 2003; Du \& Huang, 2008). The RGR value of a plant reflects its vigour and is considered a good index of its exposure to stresses of all sorts (Almansouri et al., 1999; Lutts, 2004; Yang et al., 2007). The RGR response of linseed seedlings exposed to increasing PEG concentrations (Figure $1 \mathrm{~A}, P \leq 0.05$ ), revealed a decrease for roots which was about 1.33-times greater than that for shoots (Table $2, P \leq 0.05$ ). This may reflect the impact of water stress on root cell development, which would likely impair nutrient uptake as well as having detrimental effects on photosynthesis, essential for biomass accumulation and therefore on shoot and root elongation. The change trend for WC was similar to that for RGR but the extension of WC in the shoot was about 1.17-times that of the root (Figure 1. B; Table 2; $P \leq 0.05$ ). Water stress therefore appears to reduce the absorption and utilization of water to such an extent that the tolerance mechanisms employed by these plants in a drought are insufficient to maintain normal growth.

\subsection{Effects of Water Stress on Chlorophyll Fluorescence, Chlorophyll Pigments and Light-response Curves}

The chlorophyll fluorescence kinetics react to the "intrinsic" characteristic of photosynthesis and can rapidly and sensitively reflect a plant's physiological status and its relationship with the environment (Huang et al., 2009). The observed impact of water stress on photosynthetic activity led us to investigate the mechanisms involved in greater detail by examining chlorophyll a fluorescence as an index of stress since this could provide insights into the nature of stress-induced damage to the photosynthetic apparatus (Shi et al., 2008; Chen et al., 2009). In this study, PSII values decreased with increasing PEG concentration but these began to decline significantly in $20 \%$ PEG concentration $(-0.58 \mathrm{MPa})$. The results indicate that photoinhibition occurs under water stress as a result of damage to the reaction center of photosystem II (Figure 2, $P \leq 0.05$ ). The values of Y(II), qP and ETR decreased, while those of NPQ and qN increased with increasing PEG concentrations. These results indicate that electron transport activity and the photosynthetic apparatus of linseed seedlings with certain drought-resistance are damaged. The results as previously reported, however, compare as other crops, linseed seedlings have more adaptive ability to drought environment by adjustment of itself (Cornic \& Fresneau 2002; Kocheva et al., 2004; Zhou et al., 2007).

$\mathrm{Chl}$ and $\mathrm{Car}$ are the main photosynthetic pigments of plants, so these are good indicators of the photosynthesis capability of a plant. Under water stress, with the exception of Car which barely changed, the contents of Chl $a$ and $b$ decreased slightly at first but then decreased more sharply at the 20\% PEG concentration (Table $3 ; P \leq 0.05$ ). This may be linked with the observation that under $-0.58 \mathrm{MPa}$ water potential conditions $\mathrm{Chl}$ synthesis was severely inhibited with the result that the functioning of the photosynthetic apparatus became seriously impaired. Compared with the control, the water stress effects on $\mathrm{Chl} a / b$ were high and this appears to be closely related to the metabolic regulation of $\mathrm{Chl}$; this possibility is worth further investigation. The behaviour of the 
light-response curve also tends to confirm this interpretation (Figure 3, $P \leq 0.05$ ).

\subsection{Effects of Water Stress on Carbohydrates, Proline and Betaine}

Carbohydrates are the main osmotic adjustment substances and so are important indicators of drought tolerance. Many studies have shown that the accumulation of storage carbohydrates such as fructans can counter the effects of increased drought by reducing the osmotic potential to avoid stress (Jones \& Turner, 1980; Munns \& Weir, 1981). Our results show that the TTC and fructan contents in shoots of linseed seedlings increases with increasing PEG concentration. This indicates that they may help to regulate and maintain the activity of physiological processes within the plant in a high water-stress environment by raising the osmotic potential of the cells. In contrast, the carbohydrate contents of the roots decreased markedly under water stress (Figure 4, $P \leq 0.05$ ). This indicates that under water stress, carbohydrates may be transported from the root to the shoot to offset the effects of drought which reduce the amounts of available photosynthetic products. Or the carbohydrate metabolism might be stimulated in the shoot of linseed seedlings, but the carbohydrate metabolism might be inhibited in root. This should be further investigated.

Proline and betaine are also known to play important roles in osmotic adjustment with their accumulation under water stress being observed in many species (Stewart \& Lee, 1974; Rhodes \& Hanson, 1993). Here, the results show that, along with a decrease in osmotic potential, the accumulation of free proline and betaine increased significantly both in the roots and the shoots. This increase would lower the osmotic potential (i.e. make it more strongly negative) in the cells which would help to maintain turgor and thus sustain the normal physiological and biochemical processes in the face of drought (Figure 5, $P \leq 0.05$ ).

\subsection{Effect of Water Stress Treatments on Ionic Balance}

Potassium is a major element in plants. One of its key functions is turgor maintenance and regulation and in this role it becomes involved in osmotic adjustment (Zhao et al., 2006). Under water stress conditions, the accumulation of $\mathrm{K}^{+}$in linseed seedlings was higher than of the other ions measured and, moreover, with increasing water stress, the amount of $\mathrm{K}^{+}$increased disproportionately relative to the other ions (Table 4 and 5 , $P \leq 0.05$ ). This clearly indicates that for linseed seedlings under water stress conditions, $\mathrm{K}^{+}$is the main inorganic osmolyte used to maintain essential enzymatic processes in the cytoplasm. Under drought conditions, the $\mathrm{K}^{+}$ could increase plant water keeping ability, protect the cell membrane hydration layer and keep the cell membrane stability by enhance carbon and nitrogen metabolism, and active oxygen metabolism (Egilla et al., 2001; Yamada et al., 2002; Yang et al., 2004; Jose et al., 2005). In this research, we propose that increased $\mathrm{Na}^{+}$decreased caused by water stress compare as control one. Water stress might have weakened the controls on absorption or transport of $\mathrm{Na}^{+}$, leading to the decreased of $\mathrm{Na}^{+}$content and disrupting the ionic balance. The decreased $\mathrm{Na}^{+}$ under water stress might also be related to increase $\mathrm{Na}^{+}$exclusion. It is well known that plants have a $\mathrm{Na}^{+}$ exclusion mechanism depending on a $\mathrm{Na}^{+} / \mathrm{H}^{+}$antiport, such as salt overly sensitive 1 (SOS1), which exchanges cytoplasmic $\mathrm{Na}^{+}$with external $\mathrm{H}^{+}$(Zhu, 2003). The exchange activity relies on the transmembrane proton gradient achieved by $\mathrm{H}^{+}$-ATPase (Zhu, 2003). Under water stress, the amount of external protons might stronger the exchange activity of the $\mathrm{Na}^{+} / \mathrm{H}^{+}$antiport on the root plasma membrane, inducing exclusion of $\mathrm{Na}^{+}$into the rhizosphere and enhancing in vivo accumulation.

Table 4. The fraction (\%) of each solute molarity to total molarity in shoots of linseed seedlings under water stress (in any row, the sum of the values is $100 \%$ )

\begin{tabular}{ccccccccc}
\hline Shoots & \multicolumn{4}{c}{ Cations (\%) } & \multicolumn{5}{c}{ Anions (\%) } \\
\hline & $\mathrm{K}^{+}$ & $\mathrm{Na}^{+}$ & $\mathrm{Ca}^{2+}$ & $\mathrm{Mg}^{2+}$ & $\mathrm{Cl}^{-}$ & $\mathrm{NO}_{3}^{-}$ & $\mathrm{H}_{2} \mathrm{PO}_{4}^{-}$ & $\mathrm{SO}_{4}{ }^{2-}$ \\
$\mathrm{C}$ & $20.48 \pm$ & $4.18 \pm$ & $10.71 \pm$ & $8.83 \pm$ & $6.99 \pm$ & $25.80 \pm$ & $16.01 \pm$ & $6.99 \pm$ \\
$5 \%$ & $26.36 \pm$ & $2.54 \pm$ & $10.35 \pm$ & $8.87 \pm$ & $7.03 \pm$ & $19.19 \pm$ & $18.81 \pm$ & $6.84 \pm$ \\
$10 \%$ & $23.79 \pm$ & $2.57 \pm$ & $10.87 \pm$ & $9.03 \pm$ & $7.76 \pm$ & $19.04 \pm$ & $19.58 \pm$ & $7.35 \pm$ \\
$15 \%$ & $24.48 \pm$ & $2.53 \pm$ & $10.33 \pm$ & $8.85 \pm$ & $7.67 \pm$ & $20.36 \pm$ & $18.50 \pm$ & $7.28 \pm$ \\
$20 \%$ & $22.92 \pm$ & $2.61 \pm$ & $11.00 \pm$ & $8.89 \pm$ & $7.78 \pm$ & $21.32 \pm$ & $18.25 \pm$ & $7.24 \pm$ \\
\hline
\end{tabular}


Table 5. The fraction (\%) of each solute molarity to total molarity in roots of linseed seedlings under water stress (in any row, the sum of the values is $100 \%$ )

\begin{tabular}{ccccccccc}
\hline Roots & \multicolumn{9}{c}{ Cations (\%) } & \multicolumn{5}{c}{ Anions (\%) } \\
\hline & $\mathrm{K}^{+}$ & $\mathrm{Na}^{+}$ & $\mathrm{Ca}^{2+}$ & $\mathrm{Mg}^{2+}$ & $\mathrm{Cl}^{-}$ & $\mathrm{NO}_{3}^{-}$ & $\mathrm{H}_{2} \mathrm{PO}_{4}^{-}$ & $\mathrm{SO}_{4}^{2-}$ \\
$\mathrm{C}$ & $38.56 \pm$ & $14.30 \pm$ & $7.84 \pm$ & $16.87 \pm$ & $2.26 \pm$ & $18.81 \pm$ & $1.01 \pm$ & $0.35 \pm$ \\
$5 \%$ & $42.90 \pm$ & $11.06 \pm$ & $6.85 \pm$ & $16.51 \pm$ & $2.15 \pm$ & $18.9 \pm$ & $1.30 \pm$ & $0.31 \pm$ \\
$10 \%$ & $43.38 \pm$ & $10.08 \pm$ & $7.28 \pm$ & $17.47 \pm$ & $1.87 \pm$ & $18.25 \pm$ & $1.30 \pm$ & $0.35 \pm$ \\
$15 \%$ & $43.87 \pm$ & $10.68 \pm$ & $7.62 \pm$ & $16.34 \pm$ & $1.75 \pm$ & $17.66 \pm$ & $1.77 \pm$ & $0.31 \pm$ \\
$20 \%$ & $41.61 \pm$ & $11.07 \pm$ & $7.96 \pm$ & $17.21 \pm$ & $1.59 \pm$ & $18.62 \pm$ & $1.59 \pm$ & $0.34 \pm$ \\
\hline
\end{tabular}

Calcium participates in signalling and is also involved in the cell walls, whereas $\mathrm{Mg}^{2+}$ is an important component of chlorophyll (Knight et al., 1997; Parida \& Das, 2005). The results show that water stress did not significantly affect the accumulation of $\mathrm{Ca}^{2+}$ or of $\mathrm{Mg}^{2+}$ in linseed seedlings. Meanwhile, under water stress the $\mathrm{Cl}^{-}$content appears to decrease strongly in the roots, showing a vigorous movement towards the shoots. It suggests that $\mathrm{Cl}^{-}$ could a useful indicator for studying relations between soil water status and water movement (Table 4 and 5 , $P \leq 0.05$ ). The accumulation of $\mathrm{H}_{2} \mathrm{PO}_{4}^{-}$may be associated with the rise in $\mathrm{K}^{+}$, additional anionic components being required to preserve ionic balance. Levels of $\mathrm{NO}_{3}{ }^{-}$and $\mathrm{SO}_{4}{ }^{2-}$ were not significantly affected by water stress (Table 4 and 5, $P \leq 0.05$ ).

\subsection{Effects of Water Stress on Germination}

Germination is a critical stage in the life cycle of a higher plant and is probably the stage at which it is most vulnerable to adverse external factors including to various abiotic stresses (Debez et al., 2004). Our results indicate that water stress had a strong inhibitory effect on germination, with germination rates gradually decreasing with increasing PEG concentration. Seeds treated with $15 \%$ and $20 \%$ PEG did not germinate at all, suggesting a water potential threshold for germination of linseed seeds of about $-0.36 \mathrm{MPa}$. However, many seeds that failed to germinate in a high water-stress environment germinated when water stress conditions were released (Figure 7, $P \leq 0.05$ ). This suggests that the seed of linseed has a limited capacity for osmotic adjustment with germination under high water stress conditions being significantly inhibited.

\section{Conclusion}

The effects of water stress on a number of growth, photosynthetic, physiological and germination responses were studied in linseed seedlings. Water stress was simulated by bathing the roots in solutions with different concentrations of PEG. Seedling growth was inhibited by water stress, and especially that of the roots. Water regulation occurs either just outside the root, or in the root apoplast, or in both places. Therefore, it is proposed that the physiological mechanisms involved in root adjustments to highly negative external water potentials may be key to water-stress resistance in linseed. With increasing PEG, the concentrations of PSII, DPSII, $q P$ and ETR all decreased, whereas that of $q N$ increased slightly. These responses indicate that drought stress caused light inhibition by decreasing photochemical quenching and increasing non-photochemical quenching. Together these helped the plants to adapt to the adverse water stress conditions imposed. Carbohydrate levels increased greatly in response to water stress, as did the levels of proline and betaine. This suggests that linseed seedlings may initially sense a drought environment and then offset its harmful effects by altering the distribution and accumulation of carbohydrates, proline and betaine. The effects of water stress on the distribution and accumulation of inorganic ions were not very great. The germination percentage was reduced from $57 \%$ to $63 \%$ compared to the control with decreases in osmotic potential from -0.09 to $-0.19 \mathrm{MPa}$. No germination occurred at or below $-0.36 \mathrm{MPa}$. These results provide a useful understanding of drought responses in linseed that should facilitate the development of strategies for the creation of new varieties more tolerant to water stress.

\section{Acknowledgements}

This work supported by grants from the Project of the National Natural Science Foundation of China (No. 31170303, 30870238, 30871447, 50709040, 31070398). The basic research special fund operations (No. BSRF 200901, BSRF200803), the international scientific and technological cooperation projects (No. 2010DFB30550) The basic research special fund operations (1610122012001).

\section{References}

Abrol, I. P., Yaday, J. S., \& Massoud, F. I. (1988). Salt-affected soils and their management. Food and 
Agriculture Organization of the United Nations, Rome.

Almansouri, M., Kinet, J. M., \& Lutts, S. (1999). Compared effects of sudden and progressive impositions of salt stress in three durum wheat (Triticum durum Desf.) cultivars. J. Plant Physiol., 154, 743-752. http://dx.doi.org/10.1016/S0176-1617(99)80253-3

Arnon, D. I. (1949). Copper enzymes in isolated chlorop lasts phenoloxidases in Beta Vulgaris. J. Plant Physiol., 24, 1-15. http://dx.doi.org/10.1104/pp.24.1.1

Bodros, E., Pillin, I., Montrley, N., \& Baley, C. (2007). Could biopolymers reinforced by randomly scattered flax fibre be used in structural applications? Compos. Sci. Technol., 67, 462-470. http://dx.doi.org/10.1016/j.compscitech.2006.08.024

Bush, J. K., \& Van Auken, O. W. (1991). Importance of time of germination and soil depth on growth of Prosopis glandulosa (Leguminosae) seedlings in the presence of a $\mathrm{C}_{4}$ grass. Am. J. Bot., 78, 1732-1739. http://dx.doi.org/10.2307/2444852

Chemikosova, S. B., Pavlencheva, N. V., Gur'yanov, O. P., \& Gorshkova, T. A. (2006). The effect of soil drought on the phloem fiber development in long-fiber flax. Russian Journal of Plant Physiology, 53, 656-662. http://dx.doi.org/10.1134/S1021443706050098

Chen, Y. P., Chen, Y. N., Li, W. H., \& Xu, C. X. (2009). Effect of high temperature on photosynthesis in Populus euphratica under drought condition. J. Desert Research, 29, 474-479.

Cornic, G., \& Fresneau, C. (2002). Photosynthetic carbon reduction and oxidation cycles are the main electron sinks for photosystem II activity during a mild drought. Ann. Bot., 89, 887-894. http://dx.doi.org/10.1093/aob/mcf064

Debez, A., Hamed, B. K., Grignon, C., \& Abdelly, C. (2004). Salinity effects on germination, growth, and seed production of the halophyte Cakile maritime. Plant Soil, 262, 179-189. http://dx.doi.org/10.1023/B:PLSO.0000037034.47247.67

Deyholos, M. K. (2006). Bast fiber of flax (Linum usitatissimum L.): biological foundations of its ancient and modern uses. Israel. J. Plant., 54, 273-280.

Du, Y., \& Huang, Z. L. (2008). Effects of seed mass and emergence time on seedling performance in Castanopsis chinensis. Forest. Ecol. Manag., 2495-2501. http://dx.doi.org/10.1016/j.foreco.2008.01.013

Egilla, J. N., Davies, F. T., \& Drew, L. M. C. (2001). Effect of potassium on drought resistance of HibisCuS rosasinensis CV. Leprechaun: Plant growth, leaf macto-and micronutrient content and root longevity. Plant and Soil, 229, 213-224. http://dx.doi.org/10.1023/A:1004883032383

FAO. FAO Statistical Yearbook. Food and Agriculture Organization of the United Nations, Rome.

Foster, R., Williamson, C. S., \& Lunn, J. (2009). Culinary oils and their health effects. Nutr. Bull, 34, 4-47. http://dx.doi.org/10.1111/j.1467-3010.2008.01738.x

Fournier, J. M., Roldan, A. M., \& Sanchez, C. (2005). $\mathrm{K}^{+}$starvation increases water uptake in whole sunflower plants. Plant Science, 168, 823-829. http://dx.doi.org/10.1016/j.plantsci.2004.10.015

Genty, B., Briantais, J. M., \& Baker, N. R. (1989). The relationship between the quantum yield of photosynthetic electron transport and quenching of chlorophyll fluorescence. Biochem. Biophys. Acta., 990, 87-92. http://dx.doi.org/10.1016/S0304-4165(89)80016-9

Grieve, C. M., \& Grattan, S. R. (1983). Rapid assay for determination of water-soluble quaternary-amino compounds. Plant Soil, 70, 303-307. http://dx.doi.org/10.1007/BF02374789

Huang, H. Y., Dou, X. Y., Deng, B., Wu, G. J., \& Peng, C. L. (2009). Responses of different secondary provenances of Jatropha curcas to heat stress. Silvae. Sinicae. Sci., 45, 150-155.

Huis, R., Hawkins, S., \& Neutelings, G. R. (2010). Seeselaerchc atrtiioclen of reference genes for quantitative gene expression normalization in flax (Linum usitatissimum L.). BMC. Plant. Biology, 10, 71-78. http://dx.doi.org/10.1186/1471-2229-10-71

Kingsbury, R. W., \& Epstein, E. (1984). Selection for salt resistant in spring wheat. Crop. Sci., 24, $310-315$. http://dx.doi.org/10.2135/cropsci1984.0011183X002400020024x

Knight, H., Trewavas, A. J., \& Knight, M. R. (1997). Calcium signaling in Arabidopsis thaliana responding to drought and salinity. Plant. J., 12, 1067-1078. http://dx.doi.org/10.1046/j.1365-313X.1997.12051067.x 
Kocheva, K., Lambrevb, P., Georgieva, G., Goltsevc, V., \& Karabaliev, M. (2004). Evaluation of chlorophyll fluorescence and membrane injury in the leaves of barley cultivars under osmotic stress. Bioelectrochemistry, 63, 121-124. http://dx.doi.org/10.1016/j.bioelechem.2003.09.020

Liu, H. Y., Li, J. Y., Zhao, Y., \& Huang, K. K. (2007). Influence of drought stress on gas exchange and water use efficiency of salix psammophila growing in five places. Arid. Zone. Res., 24, 815-820.

Lutts, S., Almansouri, M., \& Kinet, J. M. (2004). Salinity and water stress have contrasting effects on the relationship between growth and cell viability during and after stress exposure in durum wheat callus. Plant. Sci., 167, 9-18. http://dx.doi.org/10.1016/j.plantsci.2004.02.014

McKenzie, R. R., \& Deyholos, M. K. (2011). Effects of plant growth regulator treatments on stem vascular tissue development in linseed (Linum usitatissimum L.). Ind. Crop. Prod., 34, 1119-1127. http://dx.doi.org/10.1016/j.indcrop.2011.03.028

Munns, R. (2002). Comparative physiology of salt and water stress. Plant Cell Environ., 25, 239-250. http://dx.doi.org/10.1046/j.0016-8025.2001.00808.x

Parida, A. K., \& Das, A. B. (2005). Salt tolerance and salinity effects on plants: a review. Ecotox. Environ. Safe, 60, 324-349. http://dx.doi.org/10.1016/j.ecoenv.2004.06.010

Pawl, B. (1988). Cities and economic development: from the dawn of history to the present. Chicago: Chicago University Press.

Paz, H., \& Martinez-Ramos, M. (2003). Seed mass and seedling performance within eight species of Psychotria (Rubiaceae). Ecol., 84, 439-450. http://dx.doi.org/10.1890/0012-9658(2003)084[0439:SMASPW]2.0.CO;2

Rengasamy, P. (2002). Transient salinity and subsoil constraints to dryland farming in Australian sodic soils: an overview. Aust. J. Exp. Agric., 42, 351-361. http://dx.doi.org/10.1071/EA01111

Rhodes, D., \& Hanson, A. D. (1993). Quaternary ammonium and tertiary sulphonium compounds in higher plants. Annu. Rev. Plant Physiol. Plant Mol. Biol., 44, 357-383. http://dx.doi.org/10.1146/annurev.pp.44.060193.002041

Richards, J. F. (1990). Land transformation. In:Turner II, B.L.,et al. (Eds.), The Earth as transformed by human action. Cambridge University Press., New York, pp. 163-178.

Ross, M. A., \& Harper, J. L. (1972). Occupation of biological space during seedling establishment. J. Ecol., 60, 70-88. http://dx.doi.org/10.2307/2258041

Shi, L. X., \& Guo, J. X. (2006). Changes in photosynthetic and growth characteristics of Leymus chinensis community along the retrogression on the Songnen grassland in northeastern China. Photosynthetica, 44, 542-547. http://dx.doi.org/10.1007/s11099-006-0068-8

Shi, Z., Shi, S. Q., Xiao, W. F., \& Qi, L. W. (2008). Influence of dehydration on characteristics of chlorophyll fluorescence of detached leaves in Haloxylon ammodendron and Populus euphratica. J. Forest. Res-JPN., 21, 566-570.

Stendle, E., \& Peterson, C. A. (1998). How does water get through roots? J. Exp. Bot., 49, 775-788.

Stewart, G. R., \& Lee, J. A. (1974). The role of proline accumulation in haloplytes. Planta, 120, 279-289. http://dx.doi.org/10.1007/BF00390296

Vaisey-Genser, M., \& Morris, D. H. (2003). History of the cultivation and uses of flaxseed. In: Muir, A., Westcott, N.D. (Eds.), Flax: The Genus Linum. Taylor and Francis. New York.

Van Kooten, O., \& Snel, J. F. H. (1990). The use of chlorophyll fluorescence nomenclature in plant stress physiology. Photosynthetic, 25, 147-150. http://dx.doi.org/10.1007/BF00033156

White, A. J., \& Critchley, C. (1999). Rapid light curves: a new fluorescence method to assess the state of the photosynthetic apparatus. Photosynth. Res., 59, 63-72. http://dx.doi.org/10.1023/A:1006188004189

Yamada, S., Osaki, M., \& Shinano, T. (2002). Effect of potassium nutrition on current photosynthesized carbon distribution to carbon and nitrogen compounds among rice, soybean, and sunflower. J. of Plant Nutrition, 25(9), 1957-1973. http://dx.doi.org/10.1081/PLN-120013287

Yang, C., Chong, J., Kim, C., Li, C., Shi, D., \& Wang, D. (2007). Osmotic adjustment and ion balance traits of an alkali resistant halophyte Kochia sieversiana during adaptation to salt and alkali conditions. Plant Soil, 294, 263-276. http://dx.doi.org/10.1007/s11104-007-9251-3 
Yang, C., Jianaer, A., Li, C., Shi, C., \& Wang, D. (2008). Comparison of the effects of salt-stress and alkaline-stress on the photosynthetic production and energy storage of an alkaline-resistant halophyte Chloris virgata. Photosynthetica, 46, 273-278. http://dx.doi.org/10.1007/s11099-008-0047-3

Yang, X. E., Liu, J. X., \& Wang, W. M. (2004). Potassium internal use efficiency relative to growth vigor, potassium distribution, and carbohydrate allocation in rice genotypes. J. of Plant Nutrition, 27(5), 837-852. http://dx.doi.org/10.1081/PLN-120030674

Zhao, J. D., Fu, H., \& Wu, C. X. (2006). Effects of water stress on biomass and osmosis-regulating substance accumulations in Nitraria sphaerocarpa seedlings. Acta. Bot. Boreal. -OccidentSin., 26, 1788-1793.

Zhao, Y. J., Weng, B. Q., Wang, Y. X., \& Xu, G. Z. (2009). Plant physio-ecological responses to drought stress and its research progress. Fujian Sci and Tech of Rice and Wheat, 27, 45-50.

Zhou, Y. H., Lam, H. M., \& Zhang, J. H. (2007). Inhibition of photosynthesis and energy dissipation induced by water and high light stresses in rice. Journal of Experimental Botany, 58, 1207-1217. http://dx.doi.org/10.1093/jxb/erl291

Zhou, Y. M., Han, S. J., \& Zhang, J. H. (2002). Effect of elevated $\mathrm{CO}_{2}$ on concentration on carbohydrate and nitrogen contents in seeding foliage of three tree species in ChangBai Mountain. J. Appl. Ecol., 13, 663-666.

Zhu, G. L., Deng, X. W., \& Zuo, W. N. (1983). Determination of free proline in plants. Plant physiol., 1, 35-37.

Zhu, J. K. (2003). Regulation of ion homeostasis under salt stress. Curr Opin Cell Biol., 6, 441-445.

Zohary, D., \& Hopf, M. (2004). Domestication of plants in the old world third edition. Oxford: Oxford University Press. 